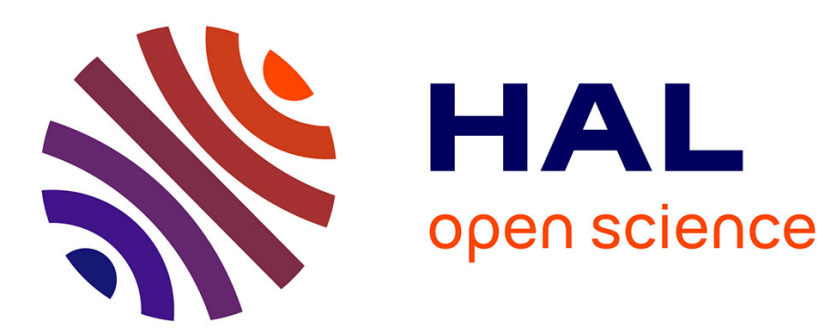

\title{
Numerical investigation of nutrient limitations in the Bohai Sea
}

\author{
Hao Liu, Baoshu Yin
}

\section{To cite this version:}

Hao Liu, Baoshu Yin. Numerical investigation of nutrient limitations in the Bohai Sea. Marine Environmental Research, 2010, 70 (3-4), pp.308. 10.1016/j.marenvres.2010.06.003 . hal-00613292

\section{HAL Id: hal-00613292 \\ https://hal.science/hal-00613292}

Submitted on 4 Aug 2011

HAL is a multi-disciplinary open access archive for the deposit and dissemination of scientific research documents, whether they are published or not. The documents may come from teaching and research institutions in France or abroad, or from public or private research centers.
L'archive ouverte pluridisciplinaire HAL, est destinée au dépôt et à la diffusion de documents scientifiques de niveau recherche, publiés ou non, émanant des établissements d'enseignement et de recherche français ou étrangers, des laboratoires publics ou privés. 


\section{Accepted Manuscript}

Title: Numerical investigation of nutrient limitations in the Bohai Sea

Authors: Hao Liu, Baoshu Yin

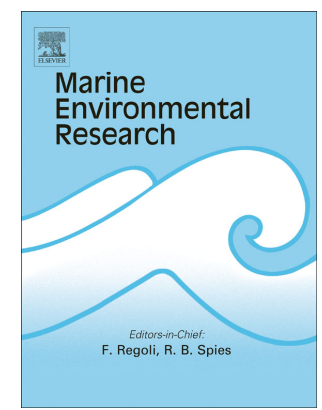

PII:

S0141-1136(10)00101-7

DOI:

10.1016/j.marenvres.2010.06.003

Reference: MERE 3460

To appear in: Marine Environmental Research

Received Date: 6 June 2007

Revised Date: 8 December 2008

Accepted Date: 21 June 2010

Please cite this article as: Liu, H., Yin, B. Numerical investigation of nutrient limitations in the Bohai Sea, Marine Environmental Research (2010), doi: 10.1016/j.marenvres.2010.06.003

This is a PDF file of an unedited manuscript that has been accepted for publication. As a service to our customers we are providing this early version of the manuscript. The manuscript will undergo copyediting, typesetting, and review of the resulting proof before it is published in its final form. Please note that during the production process errors may be discovered which could affect the content, and all legal disclaimers that apply to the journal pertain. 


\title{
Numerical investigation of nutrient limitations in
}

\author{
the Bohai Sea
}

\begin{abstract}
Hao Liu ${ }^{1 *}$ Baoshu Yin ${ }^{2}$
1 College of Marine Science, Shanghai Ocean University, 999 Hu-Cheng-Huan-Lu, Shanghai 201306,

China. Email: 1hao-tj@163.com Tel: 86-21-61900298

2 Institute of Oceanology, Chinese Academy of Sciences, 7 Nanhai Road, Qingdao 266071, China
\end{abstract}

Abstract: River discharges are the important freshwater and nutrient sources for Bohai Sea (BS), and have a profound impact on the local marine environment. In this paper, the annual cycles of nutrient and phytoplankton dynamics in 1980s were reproduced using a coupled biogeochemical-physical model. Based on the validated simulations, the nutrient limitation characters were further investigated by running the model with the riverine nutrient altered, first enriching nitrogen and then phosphorus. It was found that although the riveine $\mathrm{N}: \mathrm{P}$ ratios in Yellow and Haihe Rivers were much higher than the Redfield number, the nitrogen enrichment was still able to enhance the algae bloom in Laizhou and Bohai Bays. On the other hand, the response of algae growth to phosphorus enrichment was not thus obvious, which suggests the local phytoplankton dynamics was 
characterized by the nitrogen limitation. Simulations also show that the nitrogen enrichment is generally accompanied by the phosphorus consumption, so a shift from nitrogen limitation to phosphorus limitation may occur if such a trend continues.

Key words: N:P ratio; algae bloom; a coupled biogeochemical-physical model; Bohai Sea

\section{Introduction}

As several kinds of nutrient coexist in an aquatic environment, the phytoplankton dynamics is always limited by the one whose amount is most closely approaching the critical minimum required to sustain the algae growth (Zou et al., 2001). In the marine systems, nitrogen and phosphorus are generally thought to be two kinds of basic nutrient essential for phytoplankton photoproduction, though silicate and some other trace metal (like iron) may play a considerable role in certain regions (Shen et al., 2006; Falkowski et al., 1998, Chai, 1995). The concentrations of nitrogen and phosphorus and their elemental ratios of are known to have a straightforward effect on the local phytoplankton communities. Empirical expression of the nutrient limitation is the Redfield ratio (atomic ratio of $\mathrm{N}: \mathrm{P}:: 16: 1)$, which is the stoichiometric requirement for algae having a balanced growth (Redfield et al., 1963; Turner et al., 2003). Strong deviation from this ratio 
indicates that the nutrient in lesser supply becomes limiting for phytoplankton growth if a minimal amount is available.

During the past decades, the controversy about which nutrient is the major limiting factor to the net organic production never ceased (Smith, 1984). Since nitrogen deficits can be abated by the biological fixation of atmospheric nitrogen, one viewpoint argued that nitrogenous compounds can accumulate until phosphorus is utilized in the sea (Smith and Atkinson, 1984; Smith, 1983). On the other hand, some marine biologists suggested that nitrogen may be more limiting in coastal waters, since nitrogen fixation there is not as effective as in open oceans, and more importantly, phosphorus is generally regenerated in a faster manner in these environments (Ryther and Dunstan, 1971; Zhang and Shen, 2001; Liu et al., 2004). Nutrient enrichment experiment is an operational tool for examining the potential nutrient limitation, in which one or several nutrients are added to a given volume of water to determine if algae growth is stimulated (Zou et al., 2001). However, such in situ experiments can only be conducted on a short-time scale at several discrete sites, so it could not reflect the long term response of marine ecosystems. Numerical nutrient enrichment experiment may be a potential substitute as it can be conducted optionally. 
Bohai Sea $\left(37^{\circ} 10^{\prime} \sim 41^{\circ} 10^{\prime} \mathrm{N}, 117^{\circ} 35^{\prime} \sim 122^{\circ} 10^{\prime} \mathrm{E}\right)$ is a typical semi-enclosed shallow sea, which is located on the northwest of Pacific Ocean. Just as Figure 1 shows, it has three bays, namely Laizhou, Bohai and Liaodong Bays. The biogeochemical environment of BS is strongly influenced by tides, East Asia Monsoons and riverine inputs. Among over 40 rivers flowing into BS, Yellow, Haihe, Daliaohe and Luanhe are four major ones. Cui et al. (1996) reported that the hydrochemistry feature in BS had changed significantly in the past decades, which was characterized by the moderate increase of nitrogen, the moderate decrease of silicate, and the drastic decrease of phosphorus, respectively. How the variation in riverine nutrients influence the phytoplankton dynamics invites our interests. Therefore, by virtue of a coupled biogeochemical-physical model, two numerical experiments were conducted first to examine the response of algae growth to the variations of riverine inputs, and further to investigate its influence on the nutrient limitation characters in BS.

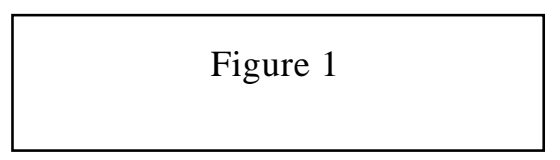

\section{Model description}

The scheme of the biogeochemical model is given in Figure 2. This model belongs 
to the Nutrient-Phytoplankton-Zooplankton-Detritus (NPZD) type, and it is coupled to a 3-dimensional baroclinic coastal ocean model developed by Blumberg and Mellor (1987). The physical model is conventionally called Princeton Ocean Model (POM), which uses the curvilinear orthogonal coordinates in the horizontal and the sigma coordinate in the vertical, respectively. The level-2.5 Mellor-Yamada turbulence closure scheme (1982) and the Smagorinski scheme are used to simulate the vertical mixing and horizontal diffusion, respectively. Advection is simulated using a one-order upwind scheme with anti-dissipation treatment, which is monotonic and positive-definite (does not permit negative values), a feature essential for the biogeochemical tracers (Christian, 2007). After some improvements, POM can be used to simulate the hydrodynamic features in BS. For example, by adding a surface wave mixing parameter to the turbulence closure model, Lin et al. (2006) captured the well-mixed warm water column apparent in summer in the central basin; by adding a surface heat budget model, Liu (2007) simulated the annual cycle of stratifications; in addition, Liu (2006) also reproduced the development of river plume in BS by introducing a river discharge model. Understanding the above physical features is essential for illustrating the biogeochemical processes.

Figure 2 
Solar radiation is used by phytoplankton for photosynthesis, and it is an important parameter for the ecosystem modeling. Therefore, a sound real-time irradiation model was developed to calculate the light intensity both on the sea surface and in the water column (Liu and Yin, 2006b). On the sea surface, solar radiation is a function of solar height and cloud parameter. Beneath the sea surface, it is not only depth-dependent, but as will be shown in equation A.10, it is also the function of pigment concentrations in the water column.

Riverine input is the important external nutrient source for BS, so a reliable river discharge model is necessary to reproduce the proper transportation of river-borne nutrient in seawaters. Following Kourafalou (2001), each river mouth is taken as a point source, from which freshwater flows into the top grid cell, inducing the sea surface height variation, so it can be written as

$$
\frac{d \eta}{d t}=\frac{Q(t)}{\Delta x \Delta y \Delta \sigma}
$$

Where, $\eta$ is sea surface elevation; $\Delta x$ and $\Delta y$ are the length and width of the top grid cell at the point source, respectively; $\Delta \sigma$ is the height of that grid cell; $Q(t)$ is the time-variable runoff. 
Similarly, river-induced variation in nutrient concentration and other scalars like temperature or salinity at the point source can also be expressed as

$$
\frac{d \varphi}{d t}=\frac{Q(t) \phi}{L \Delta x \Delta y \Delta \sigma}
$$

Where, $L=H+\eta$ is the real water depth; $\phi$ indicates the nutrient concentration, temperature or salinity in rivers; $\varphi$ denotes those variables in the ambient seawaters.

The climatological runoff of four major rivers in 1980s is given in Figure 3. Four rivers are seasonal and the freshwater inputs mainly concentrate in the wet season (from July to October). Therefore, the riverine nutrient may have relatively little influence on the algae growth in spring. In addition, Figure 3 also shows that Yellow River accounts for more than $60 \%$ freshwater inputs to BS.

Figure 3

Table 1 lists the dissolved inorganic nitrogen and phosphate concentrations in four rivers. Data in the standard case column are from Zhang et al. (2004), and data in the other two columns are adapted to the nutrient enrichment experiments. In the nitrogen enrichment experiment, the concentration of river-borne nitrogen was set to be 1.5 times that of the standard case, whereas in the phosphorus enrichment experiment, the 
concentration of riverine phosphate is set to be about one order higher than that in ambient seawaters. Sediment release is another external nutrient source for the BS ecosystem, and the sediment-water nutrient flux was estimated by Zhang et al. (2004).

Table 1

The detailed description of the biogeochemical model is given in Appendix A. For the convenience of estimating the $\mathrm{N}: \mathrm{P}$ ratio directly, we take the dissolved inorganic nitrogen (including nitrate, ammonium and nitrite) as a single material. Table 2 lists all the biological parameters used in this study.

Table 2

The coupled biogeochemical-physical model was forced by actual forcings, taking into account tides, wind and river discharges. Eight major tides- $\mathrm{K}_{1}, \mathrm{O}_{1}, \mathrm{P}_{1}, \mathrm{Q}_{1}, \mathrm{M}_{2}, \mathrm{~S}_{2}$, $\mathrm{N}_{2}$ and $\mathrm{K}_{2}$ were superimposed along the longitude of $122^{\circ} 10^{\prime} \mathrm{E}$ to simulate the tidal wave propagation through the open lateral boundary. The hourly mean wind field was interpolated and extrapolated from 14 coastal weather stations around BS. Both tidal forcing and wind stress contribute to the vertical mixing of the water column, especially 
to the transportation of sediment-borne nutrient into the euphotic zone. The detailed boundary and initial conditions are described in Appendix B.

Horizontal resolution was $5^{\prime}$ by $5^{\prime}$, and 15 sigma layers were divided in the vertical. Time steps prescribed to the external and internal mode of the physical model were 15 seconds and 450 seconds, respectively, and the biogeochemical processes were updated every 30 minutes. The model was run for 2 years, and the results of the second year were presented for analysis.

\section{Model results and analysis}

\subsection{Validation of simulations}

The annual cycle of the primary productivity and f-ratio have been successfully reproduced by Liu and Yin (2006a) using the original version of the coupled biogeochemical-physical model in which inorganic nitrogen was separated into nitrate and ammonium. In this study, much attention was paid to the nutrient limitation characters, so the simulated nutrient and phytoplankton dynamics need to be examined firstly. Figure 4 compares the simulated and observed annual cycles of nitrogen and phosphorus at the surface layer of BS, in which observations are basin wide data derived 
from the MABHE datasets (Chen et al., 1992). It was found that both nutrients are characterized by the lowest level in summer and the highest level in winter. Previous investigations in BS have shown that the seasonal variation in the phytoplankton community exhibits a double-peak structure, corresponding to spring and autumn bloom, respectively (Fei et al., 1991; Wei et al., 2004). It is the typical feature in the North Hemisphere. The onset of algae bloom is always at the cost of consumption of much nutrient, so it is not surprising to see that nutrient concentration at the surface layer has declined to a very low level as the second bloom occurs in early autumn. In winter, the nutrient stock can rapidly resume due to the algae inertia in cold waters. As for what extent the nutrient stock can return to, it mainly depends on the load of external nutrient sources and the nutrient regeneration characters.

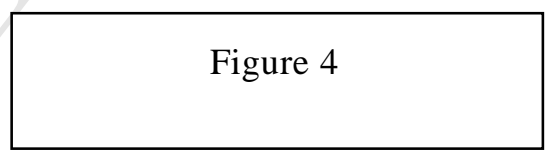

Following the conventional method, the phytoplankton biomass is expressed using the chlorophyll-a stock. Figure 5 shows the comparison of the simulated and observed annual cycle of chlorophyll-a at the surface layer, in which observations are basin wide data derived from Fei et al. (1991). Three bays are the direct receivers of river discharge 
and easily subject to the variation in riverine inputs, so we would examine them and the central basin individually. From Figure 5 it can be seen the simulations show a reasonable consistency with observations, especially in reproducing the double-peak structure, which corresponds to the spring and autumn algae blooms, respectively.

Figure 5

Figure 5 also shows that the spring bloom first occurs at shallow bays and then spreads to the relatively deep central basin, which may be correlated with the evolution of thermal stratifications in BS. Photosynthesis generally happens in the euphotic zone (less than $10 \mathrm{~m}$ in BS, see Figure 6), so the downward transport of algae induced by both tidal mixing and wind stirring causes the chlorophyll-a stock at the surface layer to accumulate slowly in the deep central basin than in shallow bays. The thermal stratification comes into being as soon as the surface heat flux can balance the turbulent kinetic energy induced by mixing mechanisms in the deep waters like the central basin or the BS strait (Liu, 2007). As a result, the vertical material exchange is effectively blocked, and the phytoplankton biomass begins to accumulate in a rapid manner in the 
euphotic zone. Therefore, it is sure for us to suggest that the evolution of thermal stratifications may be an important reason for the spring bloom to occur later in the central basin than in shallow bays.

It is interesting to note that in BS the most intense algae bloom generally occurs in spring, not in summer when is characterized by the highest level of primary productivity (Wei et al., 2004; Fei et al., 1991; Liu and Yin, 2006a). This phenomenon may be ascribed to the strong grazing pressure from zooplankton (Bai et al., 1991; Zhao et al., 2004). In addition, the drastic reduction in nutrient stock due to the onset of spring bloom may also limit the intensity of the second bloom to some extent.

Since summer is the most productive season in BS, the primary productivity profiles along a cross section (see Figure 1 for position) in august are presented to check the model results, which also could be used to examine the irradiation simulation to some extent. The observations are estimated by Zhao and Wei (2005) using the conventional chlorophyll-a method. Figure 6 shows that although the simulated euphotic zone is somewhat overestimated compared to observations, the similar patterns are achieved with the higher productivity to be centered on the top of the stratifications. The highest productivity appears between $119^{\circ} 30^{\prime}$ and $120^{\circ} 00^{\prime} \mathrm{E}$, a position within the well-mixed 
warm water column reported by Lin et al. (2006) who suggested that both tide and wind-wave induced mixing contribute to such a distinct warm water structure. Therefore, more benthic nutrient can be brought into the euphotic zone, which is essential for the algae's photo-production.

\section{Figure 6}

\subsection{Horizontal distribution of inorganic nitrogen and phosphate}

The simulated nitrogen and phosphorus at the surface layer of BS are given in Figure 7. In winter, the high level of nitrogen mainly distributes in three bays, and the central basin shows the lower nitrogen concentration (Figure 7a). Such a pattern is not surprising, because there are approximately $4.96 \times 10^{9}, 7.78 \times 10^{8}$ and $3.50 \times 10^{8} \mathrm{~mol}$ nitrogen annually discharged into Laizhou Bay, Bohai Bay and Liaodong Bay through YR, HR and DR, respectively (Zhang et al, 2004). Most of the newly inputted nutrients are firstly consumed by phytoplankton, and then through a series of biogeochemical-physical processes they are ultimately released into the local water column in winter. Contrary to the situation in winter, the nitrogen concentration has 
declined markedly in summer (Figure 7b). Nitrogen is almost exhausted in the central basin, whereas three bays can maintain a relatively high level of nitrogen due to the continuous riverine inputs.

\section{Figure 7}

For a clear specification of the influence of riverine inputs, Figure 8 gives the simulated sea surface salinity distribution in the wet season, which represents the evolution of river plume under both tide and wind forcings. As shown in Figure 8, the 30 psu contour can be approximately regarded as a partition between the river water and the ambient seawater, namely the freshwater front. It is these fronts that effectively limit the river-borne nutrients to spread into the central basin. Although the central basin lacks the riverine inputs, it has a well mixed warm water column due to both wind wave stirring and tidal mixing (Lin et al., 2006), thus more sediment-borne nutrients can be transported to the euphotic zone to sustain the second algae bloom.

\section{Figure 8}

Phosphorus shows a different distribution pattern compared to that of nitrogen, 
since the relatively high level of phosphate concentrates in the central basin rather than in the Laizhou Bay which is the direct receiver of riverine phosphate from Yellow River. The climatological N:P ratio in YR is about 350.7 (far higher than the Redfield ratio), at the meanwhile its runoff accounts for $60 \%$ of the freshwater inputs for BS, which means that much more phosphorus from the ambient seawater is consumed by phytoplankton for a balance growth. Therefore, the lowest level of phosphate appears in the Laizhou Bay no matter in winter or in summer, just contrary to the situation of nitrogen. Although the N:P ratio in Haihe River can also reach 82.2, its small runoff would not induce the over-consumption of phosphorus in the Bohai Bay. The highest level of phosphorus distributes in the Liaodong Bay, since the N:P ratio in Daliaohe River is lower than 16, meaning that newly inputted phosphorus may be surplus for algae to maintain the normal growth. In addition, the algae inertia in cold waters may play a minor role, which is correlated with the relatively low level of chlorophyll-a stock in the Liaodong Bay.

Figure 3 has shown that the N:P ratio is not constant in an annual cycle. From Figure 7 it can be further inferred that in winter, the highest N:P ratio appears in coastal waters, especially in the YR estuary where the phytoplankton dynamics shows somewhat phosphorus limitation based on the Redfield ratio. In summer, the nitrogen stock was 
almost depleted due to the intense onset of spring bloom and its weak regeneration mechanism compared to that of phosphorus. On the other hand, phosphorus shows a strong regeneration mechanism that maintains a moderate variation in the annual cycle. Therefore, in summer, the nitrogen limitation may be dominant throughout BS except the mouth of YR, where the riverine nitrogen is still able to maintain the relatively high $\mathrm{N}: \mathrm{P}$ ratio. It can be further suggested that the riverine inputs play an important role in shaping the nutrient distribution patterns in $\mathrm{BS}$, and that any drastic variations in nutrient concentrations, in $\mathrm{N}: \mathrm{P}$ ratio or in river discharges will inevitably exert a profound influence on the local nutrient and phytoplankton dynamics.

\subsection{Numerical nutrient enrichment experiments}

Based on the validated simulations, we would investigate the influence of riverine inputs on the local nutrient and phytoplankton dynamics. Two nutrient enrichment experiments were conducted. By running the coupled biogeochemical-physical model with riverine nitrogen and phosphorus altered in turn, we can examine the response of algae growth and nutrient limitations.

Figure 9, 10 and 11 respectively give the annual cycles of chlorophyll-a, nitrogen and phosphorus at four regions of BS. It was found that although the N:P ratios in YR 
and HR rivers have already been as high as 350.7 and 82.2 respectively in the standard case, the enriched river-borne nitrogen is still able to enhance the phytoplankton biomass in the Laizhou and Bohai Bays. On the contrary, as river-borne phosphate was enriched, the chlorophyll-a stock in these two bays did not display an obvious response though the concentration of riverine phosphate has increased 10 times relative to the standard case. Therefore, it can be suggested that the phytoplankton dynamics in the Laizhou and Bohai bays are still nitrogen limited by and large.

Figure 9

Figure 10 shows that in the nitrogen enrichment experiment, the nitrogen stock in Laizhou and Bohai Bays increased significantly compared to the standard case especially in winter. As a consequence of nutrient limitation, the phosphorus stock experienced some decreases (see figure 11). This phenomenon was particularly apparent in the wet season as more phosphorus was consumed to sustain the autumn algae bloom. In the phosphorus enrichment experiment, the nitrogen stock in the Laizhou Bay decreased a bit, whereas it was not that apparent in the Bohai Bay, since riverine phosphate flowing into the Laizhou Bay through YR was much more than that flowing into the Bohai Bay 
through HR.

Figure 10

The Liaodong Bay shows a different situation from two other bays, as the chlorophyll-a stock did not change very much compared to the standard case, no matter the nitrogen enrichment or the phosphorus enrichment was performed. Similarly, nitrogen and phosphorus contents were also kept at a relatively constant level in two numerical experiments. The Liaodong Bay is the largest in area among three bays, whereas the nitrogen load through DR is the lowest among four rivers. Although the phosphate concentration in DR is the highest, the river-borne phosphate seemed not to enhance the phytoplankton biomass in a nitrogen-limited environment. In addition, the riverine nutrients through DR were basically confined to the northern end of the bay due to the evolution of river plume (see Figure 8), thus the response of algae to the variation in riverine nutrients is not significant in terms of the whole bay. The central basin also displayed some nitrogen limited characters, as the enriched nitrogen can lead to the higher chlorophyll-a stock during two algae blooms whereas the enriched phosphorus does not. 
Figure 11

Although the BS ecosystem is nitrogen limited as a whole, it won't prevent the appearance of phosphorus limitation in certain regions or at certain times, especially in the YR estuary. Our simulations indicate that the increase of one nutrient stock is always accompanied by the decrease of the other one. Therefore, it can be suggested that the local nutrient limitation characters are changeable, largely depending on the composition and load of external nutrients.

\section{Discussion}

Observations at different times (Kang, 1991; Wei et al., 2004) have shown that diatom is always the dominant algae species in BS, so silicate may play an important role in the phytoplankton dynamics. Although the silicate stock has decreased a lot since late 1950s, it is still high enough to avoid from becoming the limiting nutrient (Cui et al., 1991; Zhang et al., 2004). Therefore, we did not take it into account in the present modeling. However, if the river discontinuity, which is generally thought to be the major reason for the reduction of silicate in BS, is not ameliorated, or if there is no other 
makeup mechanism yet, the continuous decrease in silicate stock will enable it a potential limiting factor in the future.

Despite phosphorus inputs through river discharge did not change very much in past decades, the nitrogen inputs increased in a rapid manner at the meanwhile. Therefore, we thought it is the mutual competition and limitation between two nutrients that lead to the continuous decrease in phosphorus stock in BS, as one nutrient increases more quickly, the other one will suffer from the ultimate decrease. Accordingly, the nutrient limitation characters may undergo a corresponding shift in the long term as a response to the changes in N:P ratios. In fact, Zou et al. (2001) has detected phosphorus limitation in the middle of Laizhou Bay in spring 1999 by means of in situ nutrient enrichment, whereas it only occurred within the YR estuary in our modeling (not shown).

Except the riverine input and sediment release, the atmospheric dropping and sewage diffuser may be other potential external nutrient sources, since diversified chemicals or fertilizers are widely utilized in recent years with the rapid development of the regional economy around BS. However, in view that our job mainly focus on the situation early in 1980s, the nutrient sources from atmospheric dropping and sewage are not considered due to their negligible load compared to that of riverine inputs and 
sediment release.

\section{Conclusion}

A relatively simple biogeochemical-physical model was used to reproduce the seasonal variation of nutrients and chlorophyll-a in BS. Compared to the complicated model studies (Wei et al., 2004; Zhao and Wei, 2005), our simulations seemed more consistent with observations, especially in revealing the nutrient and phytoplankton dynamics. It is not surprising, as the complex model generally needs to handle more biological parameters, whose uncertainty may deteriorate the model quality by and large. Similar situation has been found by Radach and Moll (2006), who suggested that more complexity in the model does not necessarily improve the simulations.

Based on the validated simulations, the nutrient limitation characters were further investigated by running the model with the riverine nutrients altered, first enhancing nitrogen concentration and then phosphorus. The nutrient enrichment experiments show that the BS ecosystem dynamics was mainly limited by nitrogen as a whole early in 1980s, though phosphorus limitation seems apparent in certain regions like the estuary of Yellow River due to the much more external inputs of riverine nitrogen. Numerical 
experiments also show that the increase of nitrogen stock was at the cost of phosphorus reduction, implying that a shift from nitrogen limitation to phosphorus limitation may occur if the nitrogen enrichment continues.

\section{Appendix A: Biological Model}

The coupled biogeochemical-physical processes are formulated as follows

$$
\begin{aligned}
& \frac{d\left(N_{n}\right)}{d t}=-\min \left\{P_{n}, P_{p}\right\}+\mu Z+r_{e} P+\varepsilon_{n} D+\operatorname{diff}\left(N_{n}\right)+S_{n} \\
& \frac{d\left(N_{p}\right)}{d t}=-\min \left\{P_{n}, P_{p}\right\}+\mu Z+r_{e} P+\varepsilon_{p} D+\operatorname{diff}\left(N_{p}\right)+S_{p} \\
& \frac{d(P)}{d t}=\min \left\{P_{n}, P_{p}\right\}-G-r_{e} P-m_{p} P+\operatorname{diff}(P) \\
& \frac{d(Z)}{d t}=\gamma G-\mu Z-M+\operatorname{diff}(Z) \\
& \frac{d(D)}{d t}=(1-\gamma) G+m_{p} P+M-\frac{1}{L} \frac{\partial\left(w_{D} D\right)}{\partial \sigma}-\varepsilon_{p} D+\operatorname{diff}(D)
\end{aligned}
$$

In which $N_{n}, N_{p}$ represents the concentration of dissolved inorganic nitrogen (mmol $\mathrm{N}$ $\mathrm{m}^{-3}$ ) and phosphate $\left(\mathrm{mmol} \mathrm{P} \mathrm{m}^{-3}\right)$, respectively, and $P, Z, D$ represents the biomass of

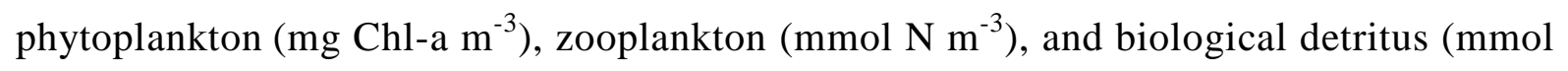
$\mathrm{N} \mathrm{m}^{-3}$ ), respectively. Diatom is the dominant algae species in BS, and the ratios of carbon to chlorophyll-a and to phosphate in diatom are about $38 \mathrm{~g} \mathrm{C} / \mathrm{g} \mathrm{Chl-a}$ and $0.97 \mathrm{~g} \mathrm{C} / \mathrm{mmol}$ 
P, respectively (Wei et al., 2004). Following the Redfield assumption, we further obtained the ratios of phosphate and nitrogen to chlorophyll-a, which are about 39.14 mmol P/g Chl-a and $0.626 \mathrm{mmol} \mathrm{N} / \mathrm{mg}$ Chl-a, respectively. These values can be used to convert the unit of phytoplankton biomass between mmol N (P) $\mathrm{m}^{-3}$ (integration process) and mg Chl-a $\mathrm{m}^{-3}$ (initial condition and model result).

The absolute derivative and diffusion terms are respectively expressed as

$$
\begin{aligned}
& \frac{d C_{i}}{d t}=\frac{\partial C_{i}}{\partial t}+\frac{\partial u C_{i}}{\partial x}+\frac{\partial v C_{i}}{\partial y}+\frac{1}{L} \frac{\partial \omega C_{i}}{\partial \sigma} \\
& \operatorname{diff}\left(C_{i}\right)=\frac{\partial}{\partial x}\left(A_{H} \frac{\partial C_{i}}{\partial x}\right)+\frac{\partial}{\partial y}\left(A_{H} \frac{\partial C_{i}}{\partial y}\right)+\frac{1}{L} \frac{\partial}{\partial \sigma}\left(\frac{K_{H}}{L} \frac{\partial C_{i}}{\partial \sigma}\right)
\end{aligned}
$$

Where, $C_{i}(i=1 \ldots 5)$ corresponds to $N_{n}, N_{p}, P, Z, D$, respectively; $u, v, \omega$ denotes the velocity component along $x, y, \sigma$ direction, respectively; $A_{H}, K_{H}$ denotes the horizontal and vertical diffusivity, respectively. $L=H+\eta$ in which $H, \eta$ indicates the water depth and surface elevation, respectively.

As nitrogen and phosphorus coexist in an aquatic ecosystem, the algae growth is generally limited by the insufficient one. The term $\min \left\{P_{n}, P_{p}\right\}$ is used to reflect this case, and the consumed nitrogen $P_{n}$ and phosphorus $P_{p}$ can be respectively expressed as

$$
P_{n}=V_{p} \exp (0.05 T) \cdot \frac{I}{I_{\text {opt }}} \exp \left(1-\frac{I}{I_{\text {opt }}}\right) \cdot \frac{N_{n}}{K_{D I N}+N_{n}} \cdot P
$$




$$
P_{p}=V_{p} \exp (0.05 T) \cdot \frac{I}{I_{o p t}} \exp \left(1-\frac{I}{I_{o p t}}\right) \cdot \frac{N_{p}}{K_{P O 4}+N_{p}} \cdot P
$$

where $T$ is seawater temperature.

Dissolved C: N: P generally changes at the ratios of 106: 16: 1 due to biological processes in seawaters (Redfield et al., 1963), a link generally used in marine ecological modeling. If $P_{p}<P_{n}$, the calculation follows the phosphorus flow, which means that the consumed phosphorus is determined first, and then the consumed nitrogen is 16 times the consumed phosphorus. Otherwise, the integration follows the nitrogen flow, which means that consumed nitrogen is obtained first, and then the consumed phosphorus is calculated by dividing the consumed nitrogen by 16 . The $\mathrm{N}: \mathrm{P}$ ratios in phytoplankton respiration and zooplankton excretion processes also abide by the Redfield assumption.

In equation (A.8) and (A.9) the solar radiation in the water column $I$ is expressed as

$$
I=\operatorname{par} \cdot I_{0} \exp \left(-k_{w} z-k_{c h l} \int_{-z}^{0} P d z\right)
$$

Where, $z$ is the distance to the sea surface; $I_{0}$ denotes light intensity on the sea surface, and is calculated through a real-time irradiation model (Liu and Yin, 2006b).

The $G$ term reflects the process of zooplankton grazing on phytoplankton based on the first type of the Michaelis-Menten equation (Steele and Henderson, 1992), as 
$G=\frac{\gamma Z P}{K_{P h y}+P} \exp (0.01 T)$

It should be stressed that the impact of fish grazing on zooplankton is also implicitly included in the present modeling by defining zooplankton mortality as a function of temperature, as follows:

$$
M=m_{z} Z \exp (0.03 T)
$$

Such a model design is proved to be crucial for reproducing the second algae bloom (Yu et al., 1999).

$S_{n}, S_{p}$ denote river-borne nitrogen and phosphorus, respectively.

\section{Appendix B: Boundary and initial conditions}

At the sea surface, the model was forced by the monthly SST and SSS climatology,

respectively, which were derived from historical observations (Chen et al., 1992). The nutrient loads via atmospheric deposition were assumed negligible compared to riverine inputs. Therefore, the surface and bottom boundary conditions were written as

$$
\left.\begin{array}{l}
\frac{K_{M}}{L}\left[\frac{\partial u}{\partial \sigma}, \frac{\partial v}{\partial \sigma}\right]=-\rho_{a} C_{s}\left[U_{10}^{2}+V_{10}^{2}\right]^{1 / 2}\left(U_{10}, V_{10}\right) \\
\omega(0)=0 \\
\frac{K_{H}}{L}\left[\frac{\partial T}{\partial \sigma}, \frac{\partial S}{\partial \sigma}, \frac{\partial N_{n}}{\partial \sigma}, \frac{\partial N_{p}}{\partial \sigma}, \frac{\partial P}{\partial \sigma}, \frac{\partial Z}{\partial \sigma}, \frac{\partial D}{\partial \sigma}\right]=0
\end{array}\right\} \quad \sigma \rightarrow 0
$$




$$
\left.\begin{array}{l}
\frac{K_{M}}{L}\left[\frac{\partial u}{\partial \sigma}, \frac{\partial v}{\partial \sigma}\right]=C_{b}\left[u_{b}^{2}+v_{b}^{2}\right]^{1 / 2}\left(u_{b}, v_{b}\right) \\
\omega(-1)=0 \\
\frac{K_{H}}{L}\left[\frac{\partial T}{\partial \sigma}, \frac{\partial S}{\partial \sigma}, \frac{\partial P}{\partial \sigma}, \frac{\partial Z}{\partial \sigma}, \frac{\partial D}{\partial \sigma}\right]=0 \\
\frac{K_{H}}{L}\left[\frac{\partial N_{n}}{\partial \sigma}, \frac{\partial N_{p}}{\partial \sigma}\right]=\left(F_{n}, F_{p}\right)
\end{array}\right\} \quad \sigma \rightarrow-1
$$

where $S$ denotes sea water salinity; $K_{M}$ is the vertical kinetic viscosity; $\rho_{a}$ is air density;

$U_{10}, V_{10}$ denote the wind speed $10 \mathrm{~m}$ above the sea surface along the $x, y$ direction,

respectively; $u_{b}, v_{b}$ are the bottom friction velocity along the $x, y$ direction, respectively;

$C_{s}, C_{b}$ are the sea surface and bottom drag coefficient, respectively; $F_{n}, F_{p}$ are nitrogen

and phosphorus flux between sediment and water exchange, respectively.

The Flather and Orlanski radiation conditions (Palma and Matano, 2000) were used on the open lateral boundary for the normal component of the external and internal velocity field, respectively. The latter allows the internal wave to pass through the BS strait with little reflection. The temperature, salinity, nitrogen, phosphate and chlorophyll-a were restored toward the monthly climatology (Chen et al., 1992) on the open lateral boundary, whereas the open boundary values of zooplankton and detritus were estimated using an upstream advection scheme (Palma and Matano, 2002) owing to the unavailability of the investigated data. 
The initial concentrations of nitrogen, phosphate, zooplankton and detritus were set to be $4.21 \mathrm{mmol} \mathrm{N} \mathrm{m}{ }^{-3}, 0.5 \mathrm{mmol} \mathrm{P} \mathrm{m}^{-3}, 0.2 \mathrm{mmol} \mathrm{N} \mathrm{m}{ }^{-3}, 0.2 \mathrm{mmol} \mathrm{N} \mathrm{m}{ }^{-3}$, respectively, and the phytoplankton biomass is set to be $1 \mathrm{mg}$ chlorophyll-a $\mathrm{m}^{-3}$, which are the mean values in winter (Zhao et al., 2004).

\section{Acknowledgement}

This study was supported by the key subject fund of Shanghai Education Committee (J50702) and the Innovation Project of Chinese Academy of Sciences (KZCX2-YWQ07-01, KZCX2-YW-BR-215-3)

\section{Reference}

Anderson, T. R., 1993. A spectrally averaged model of light penetration and photosynthesis. Limnology and Oceanography, 38, 1403-1419.

Bai, X., Zhuang, Z., 1991. Studies on the fluctuation of zooplankton biomass and its main species number in the Bohai Sea. Marine Fisheries Research, 12, 71-92. (in Chinese)

Blumberg, A. F., Mellor, G. L., 1987. A description of a three-dimensional coastal ocean 
circulation model, in Three-Dimensional Coastal Ocean Models, Vol. 4, edited by N.

Heaps, pp. 208, American Geophysical Union, Washington, D.C., 1-16.

Chai, F., 1995. Origin and maintenance of high nitrate condition in the Equatorial Pacific,

a biological-physical model study. Ph. D Thesis. Duke University, 169pp.

Chen, C. S., Ji, R. B., Zheng, L. Y., 1999. Influence of physical process on the ecosystem in Jiaozhou Bay: a coupled physical and biological model experiment. Journal of Geophysical Research, 104, C12, 29925-29949.

Chen, G. Z., Niu, G. Y., Wen, S. C., et al., 1992. Marine Atlas of Bohai Sea, Huanghai Sea, East China Sea. Beijing, Ocean Press. (In Chinese)

Christian, J. R., 2007. Advection in plankton models with variable elemental ratios. Ocean Dynamics, 57, 63-71.

Cui, Y., Chen, B., Ren, S., et al., 1996. Study on status of bio-physic-chemical environment in the Bohai Sea. Journal of Fishery Sciences of China, 3(2), 1-12. (in Chinese)

Falkowski, P. G., Richard, T. B., Victor, S., 1998. Biogeochemical controls and feedbacks on ocean primary productivity. Science, 281, 200-206.

Fasham, M. J.R., 1995. Variations in the seasonal cycle of biological production in 
subarctic oceans: a model sensitivity analysis. Deep-Sea Research I, 42(7),

1111-1149.

Fei, Z., Mao, X., Zhu, M., et al., 1991. The study on the primary productivity in the Bohai Sea- chlorophyll $a$, primary productivity and potential fisheries resources. Marine Fisheries Research, 12, 55-69. (in Chinese)

Fennel, K., 2001. The generation of phytoplankton patchiness by mesoscale current patterns. Ocean Dynamics, 52, 58-72.

Inga, H., Ralph, T., Aike, B., 2003. Regional and inter-annual variability of ecosystem dynamics in the Southern Ocean. Ocean Dynamics, 53, 1-10.

Kang, Y., 1991. Distribution and seasonal variation of phytoplankton in the Bohai Sea. Marine Fisheries Research, 12, 31-54. (in Chinese)

Kourafalou, V. H., 2001. River plume development in semi-enclosed Mediterranean regions: North Adriatic Sea and Northwestern Aegean Sea. Journal of Marine Systems, 30, 181-205.

Lin, X., Xie, S., Chen, X., et al., 2006. A well-mixed warm water column in the central Bohai Sea in summer: effects of tidal and surface wave mixing. Journal of Geophysical Research, 111, C11017, 1-8. 
Liu, H., 2006. Model study on the influence of wind and tide on the evolution of river plumes. Journal of Graduate School of Chinese Academy of Sciences, 23(6), 744-751. (in Chinese)

Liu, H., Yin, B., 2006a. Model study on Bohai ecosystem: 1. model description and primary productivity. Acta Oceanologica Sinica, 25(4), 77-90.

Liu, H., Yin, B., 2006b. A real-time irradiation model. Oceanologia Et Limnologia Sinica, 37(6): 493-497. (in Chinese)

Liu, H., 2007. Annual cycle of stratification and tidal fronts in the Bohai Sea: A model study. Journal of Oceanography, 63(1), 67-75.

Liu, S., Zhang, J., Li, D., 2004. Phosphorus cycling in sediments of the Bohai Sea and Yellow Sea. Estuarine, Coastal and Shelf Science, 59, 209-218.

Mellor, G. L., Yamada, T., 1982. Development of a turbulence closure model for geophysical fluid problems. Reviews of Geophysics and Space Physics, 1982, 20, $851-875$.

Palma, E. D., Matano, R. P., 2000. On the implementation of open boundary conditions for a general circulation model: the three-dimensional case. Journal of Geophysical Research, 105, C4, 8605-8627. 
Radach, G., Moll, A., 2006. Review of three-dimensional ecological modelling related to the North Sea shelf system. Part II: Model validation and data needs. Oceanography and Marine Biology, 44, 1-60.

Redfield, A. C., Ketchum, B., Richards, F. A., 1963. The influence of organisms on the composition of seawater. In The Sea, Vol.2, edited by Hill M. N. New York, Wiley Interscience, 26-77.

Ryther, J. H., Dunstan, W. M., 1971. Nitrogen, phosphorous, and eutrophication in the coastal marine environment. Science, 171, 1008-1013.

Shen, Z., Liu, Q., Wu, Y., et al., 2006. Nutrient structure of seawater and ecological responses in Jiaozhou Bay, China. Estuarine, Coastal and Shelf Science, 69, 299-307.

Smith, S. V., Atkinson, M. J., 1984. Phosphorous limitation of net production in a confined aquatic ecosystem. Nature, 307, 626-627.

Smith, S. V., 1984. Phosphorous versus nitrogen limitation in the marine environment. Limnology and Oceanography, 29(6), 1149-1160.

Smith, V. H., 1983. Low nitrogen to phosphorous ratios favor dominance by blue-green algae in lake phytoplankton. Science, 221, 669-671. 
Steele, J. H., Henderson, E. W., 1992. The role of predation in plankton models. Journal of Plankton Research, 14(1), 157-172.

Turner, R. E., Nancy, N. R., Dubravko, J., et al., 2003. Future aquatic nutrient limitations. Marine Pollution Bulletin, 46, 1032-1034.

Wei, H., Sun, J., Moll, A., et al., 2004. Plankton dynamics in the Bohai Sea- observations and modeling. Journal of Marine System, 44, 233-251.

Yu, G., Wu, Z., Zhang, Z., et al., 1999. A pelagic ecosystem model and Simulation of the Northern Part of Jiaozhou Bay: 1. Introduction to pelagic ecosystem Model. Journal of Ocean University of Qingdao, 29(3), 421-428. (in Chinese)

Zhang, J., Yu, Z. G., Rabbc, T., et al., 2004. Dynamics of inorganic nutrient in the Bohai seawaters. Journal of Marine System, 44, 189-212.

Zhang, P., Shen, Z., 2001. Waters characteristics of nutrient limitation. Marine Sciences, 25(6), 16-19. (in Chinese)

Zhang, Z., Zhu, M., Wang, Z., et al., 2006. Monitoring and managing pollution load in Bohai Sea, PR China. Ocean and Coastal Management, 49, 706-716.

Zhao, L, Wei, H., 2005. The influence of physical factors on the variation of phytoplankton and nutrients in the Bohai Sea. Journal of Oceanography, 61, 
$335-342$

Zhao, Q., Tian, J., Zhao, S., et al. 2004. Winter and summer chlorophyll-a and nutrient distribution and characteristics in the Bohai Sea. Marine Sciences, 28(4), 34-39. (in Chinese)

Zou, L., Zhang, J., Pan, W., et al., 2001. In situ nutrient enrichment experiment in the Bohai Sea and Yellow Sea. Journal of Plankton Research, 23(10), 1111-1119. 
Table 1 Concentrations $(\mu \mathrm{M})$ of nitrogen and phosphorus in four rivers

\begin{tabular}{ccccccc}
\hline River & \multicolumn{2}{c}{ Standard case } & & Nitrogen enrichment & \multicolumn{2}{c}{ Phosphorus enrichment } \\
& nitrogen & phosphorus & nitrogen & phosphorus & nitrogen & phosphorus \\
\hline Yellow & 126.26 & 0.36 & 189.39 & 0.36 & 126.26 & 3.6 \\
Haihe & 114.2 & 1.39 & 171.3 & 1.39 & 114.2 & 4.17 \\
Luanhe & 74.2 & 0.51 & 111.3 & 0.51 & 74.2 & 4.08 \\
Daliaohe & 23.2 & 1.71 & 34.8 & 1.71 & 23.2 & 3.42 \\
\hline
\end{tabular}


Table 2 Biological parameters

\begin{tabular}{lllll}
\hline Parameter & Value & Unit & Reference \\
\hline Light attenuation due to seawater itself $\left(k_{w}\right)$ & 0.15 & $\mathrm{~m}^{-1}$ & This study \\
Light attenuation by chlorophyll- $a\left(k_{c h l}\right)$ & 0.025 & $\mathrm{mg}^{-1} \mathrm{~m}^{-2}$ & Anderson, 1993 \\
Optimal light intensity for photosynthesis $\left(I_{\text {opt }}\right)$ & 96.9 & $\mathrm{~W} \mathrm{~m}^{-2}$ & Yu et al, 1999 \\
Phytoplankton maximum growth rate at $0^{\circ} \mathrm{C}\left(V_{p}\right)$ & 1.5 & $\mathrm{~d}^{-1}$ & Chen et al, 1999 \\
Half saturation const. for nitrogen uptake $\left(K_{D I N}\right)$ & 1.8 & $\mathrm{mmol} \mathrm{m}^{-3}$ & Zou et al., 2001 \\
Phytoplankton mortality $\left(m_{p}\right)$ & 0.05 & $\mathrm{~d}^{-1}$ & Wei et al., 2004 \\
Phytoplankton respiration rate $\left(r_{e}\right)$ & 0.1 & $\mathrm{~d}^{-1}$ & Wei et al., 2004 \\
Fraction of short wave available for photosynthesis $(p a r)$ & 0.43 & $\mathrm{Non}^{-\mathrm{d}}$ & Anderson, 1993 \\
Half saturation const. for algae phosphate uptake $\left(k_{P O 4}\right)$ & 0.13 & $\mathrm{mmol} \mathrm{m}^{-3}$ & Zou et al., 2001 \\
Rate of detritus re-mineralization to nitrogen $\left(\mathcal{E}_{n}\right)$ & 0.03 & $\mathrm{~d}^{-1}$ & Inga et a.l, 2003 \\
Half saturation const. for zooplankton grazing $\left(K_{P h y}\right)$ & 1.0 & $\mathrm{mmol} \mathrm{m}^{-3}$ & Steele et al., 1992 \\
Zooplankton assimilation efficiency $(\gamma)$ & 0.6 & $\mathrm{Non}^{-\mathrm{d}}$ & Chai, 1995 \\
Zooplankton maximum grazing rate $(g)$ & 1.0 & $\mathrm{~d}^{-1}$ & Chai, 1995 \\
Zooplankton excretion rate $(\mu)$ & 0.1 & $\mathrm{~d}^{-1}$ & Fasham et al, 1995 \\
Zooplankton mortality rate at $0^{\circ} \mathrm{C}\left(m_{z}\right)$ & 0.025 & $\mathrm{~d}^{-1}$ & Fennel et al., 2001 \\
Rate of detritus re-mineralization to phosphorus $\left(\mathcal{E}_{p}\right)$ & 0.06 & $\mathrm{~d}^{-1}$ & Zhang \& Shen, 2001 \\
\hline Vertical sinking velocity for detritus $w_{D}$ & 1.0 & $\mathrm{~m} \mathrm{~d}^{-1}$ & Fasham et al, 1995 \\
\hline
\end{tabular}




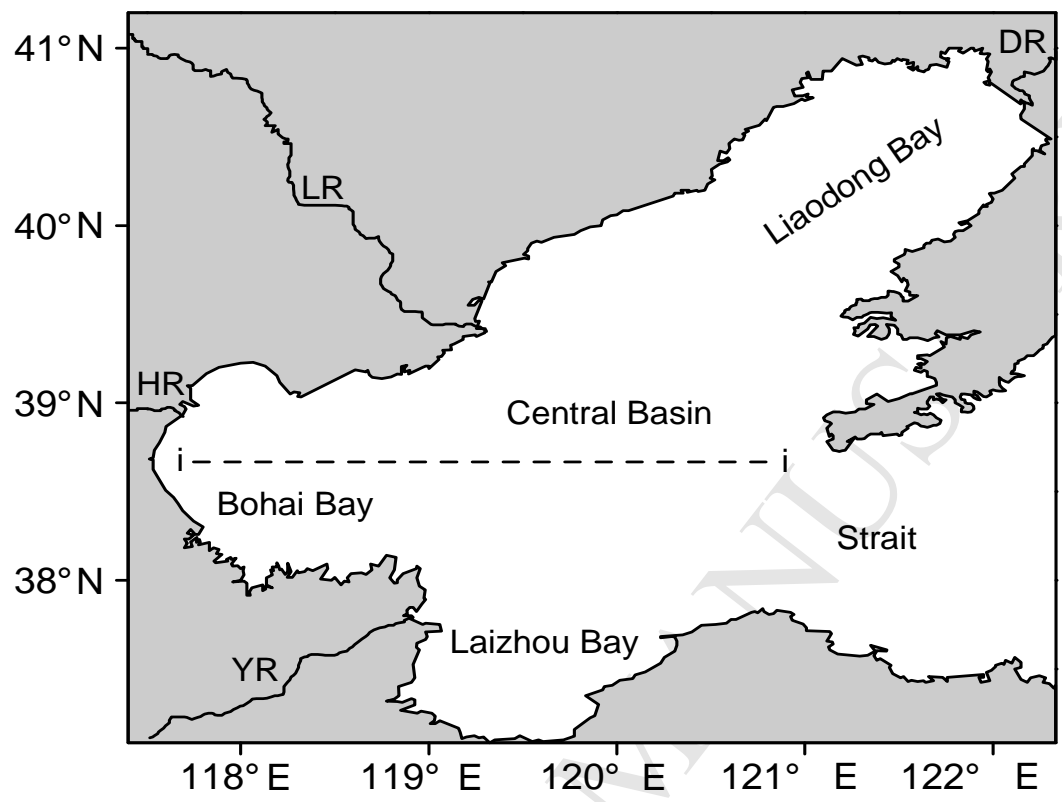

Fig.1 Bohai Sea. Four major river discharges: YR-Yellow River, HR-Haihe River,

LR-Luanhe River, DR-Daliaohe River. Dashed line i-i denotes a cross section along the latitude of $38^{\circ} 40^{\prime} \mathrm{N}$. 


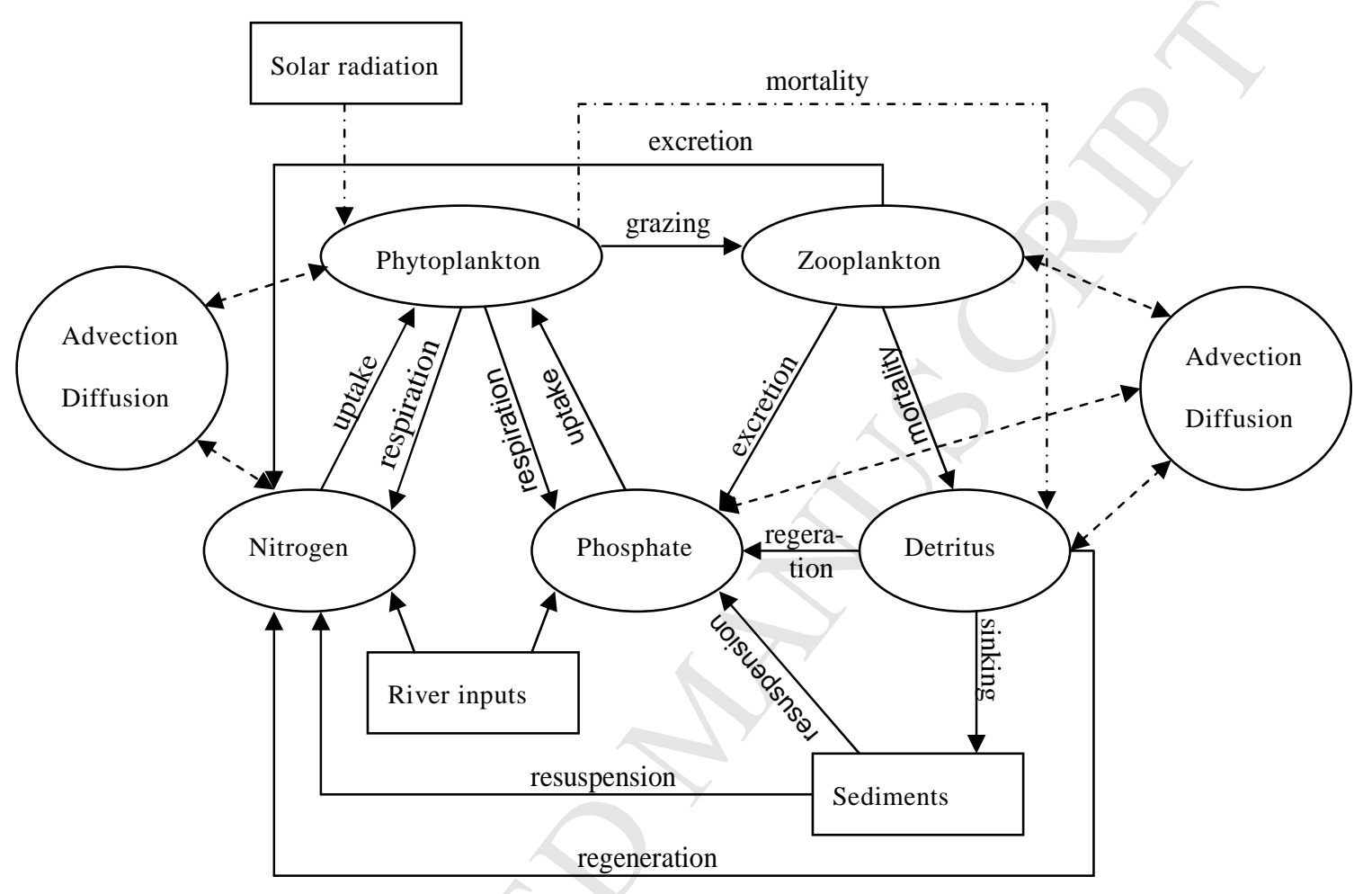

Fig.2 Scheme of the biogeochemical model 


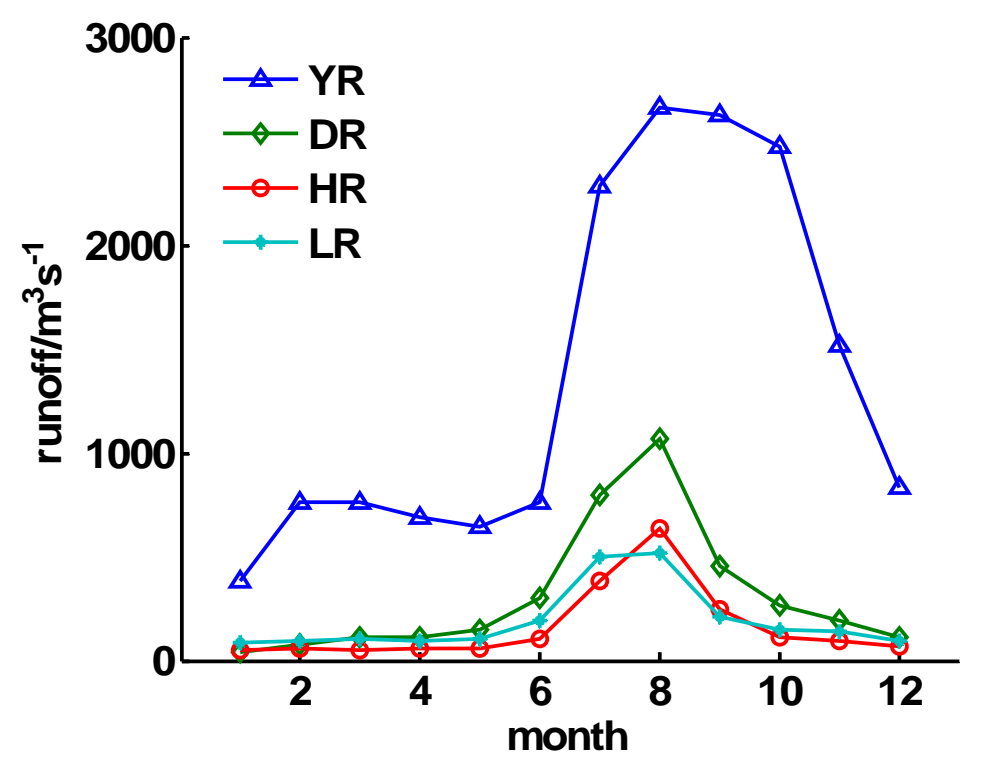

Fig.3 Monthly mean discharge of four major rivers: YR-Yellow River, HR-Haihe River, LR-Luanhe River, DR-Daliaohe River. 

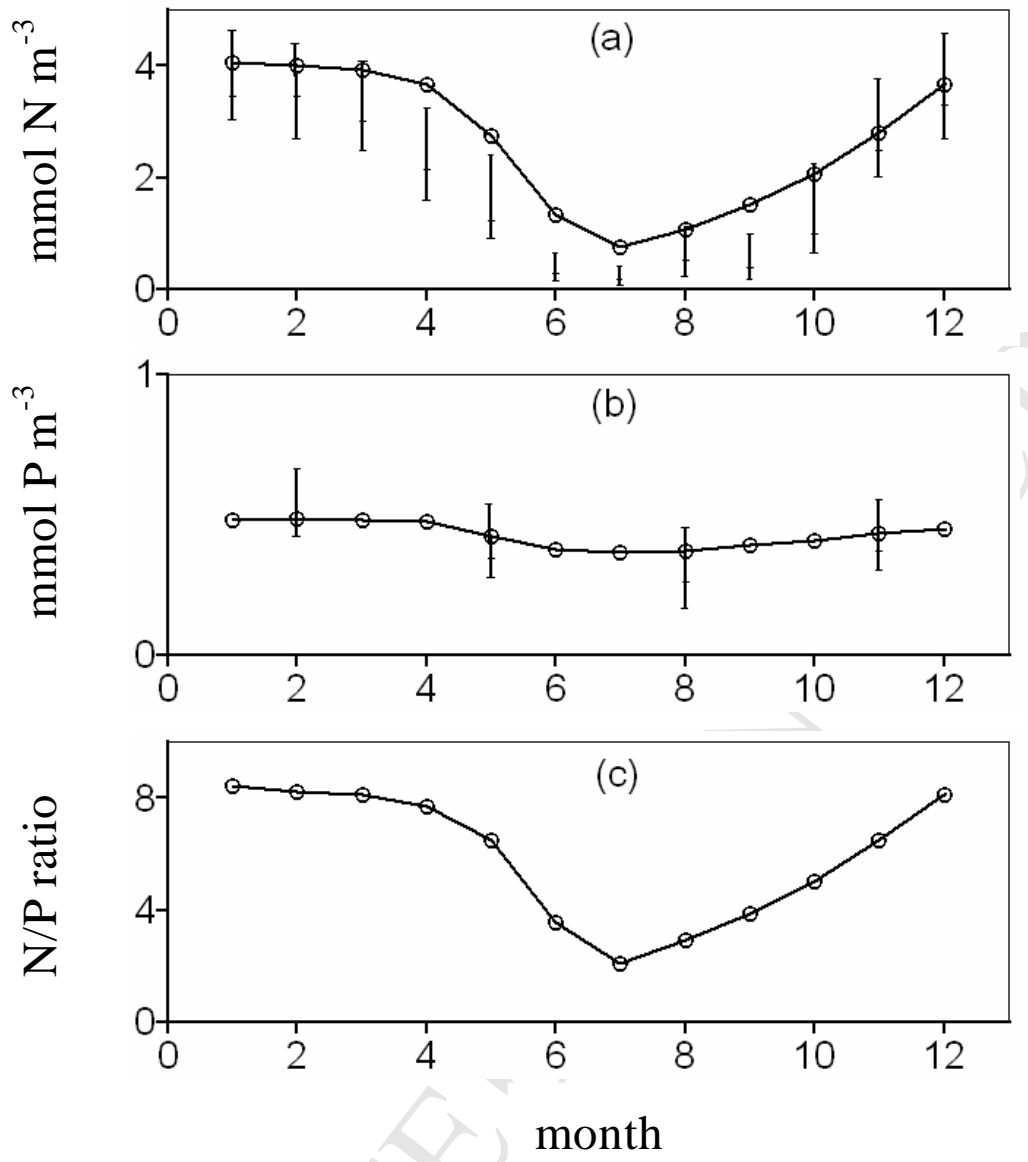

Fig.4 Annual cycles of simulated by our model (solid line with open circles), compared to monthly mean observations (error bars) from the MABHE datasets (Chen et al., 1992), for (a) nitrogen, (b) phosphate, and (c) N/P ratio in BS. 

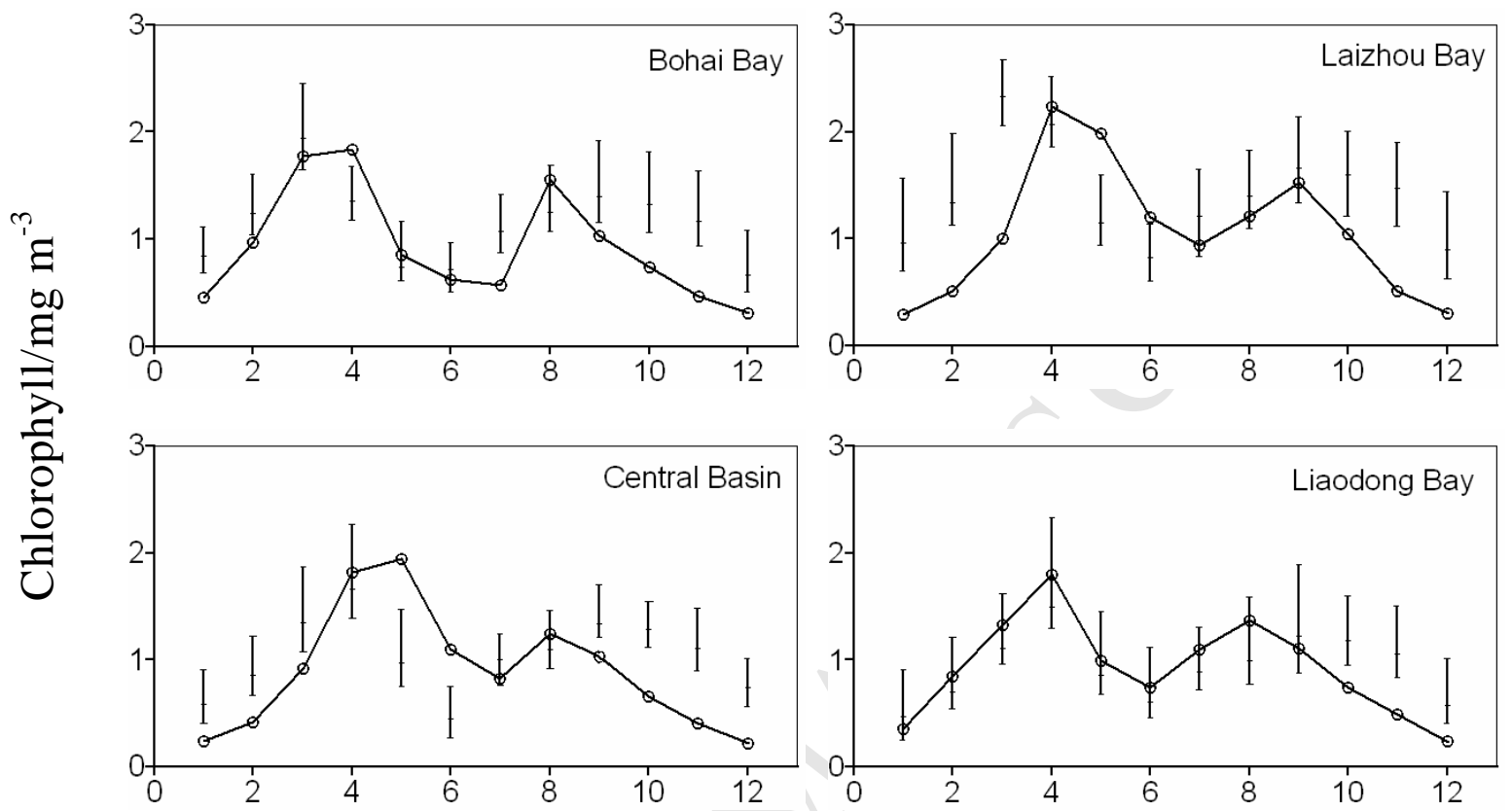

month

Fig.5 Annual cycles of simulated (solid line with open circles) and observed (error bars) chlorophyll $a$ in four regions of BS. Observations are basin wide data derived from Fei et al. (1991) 

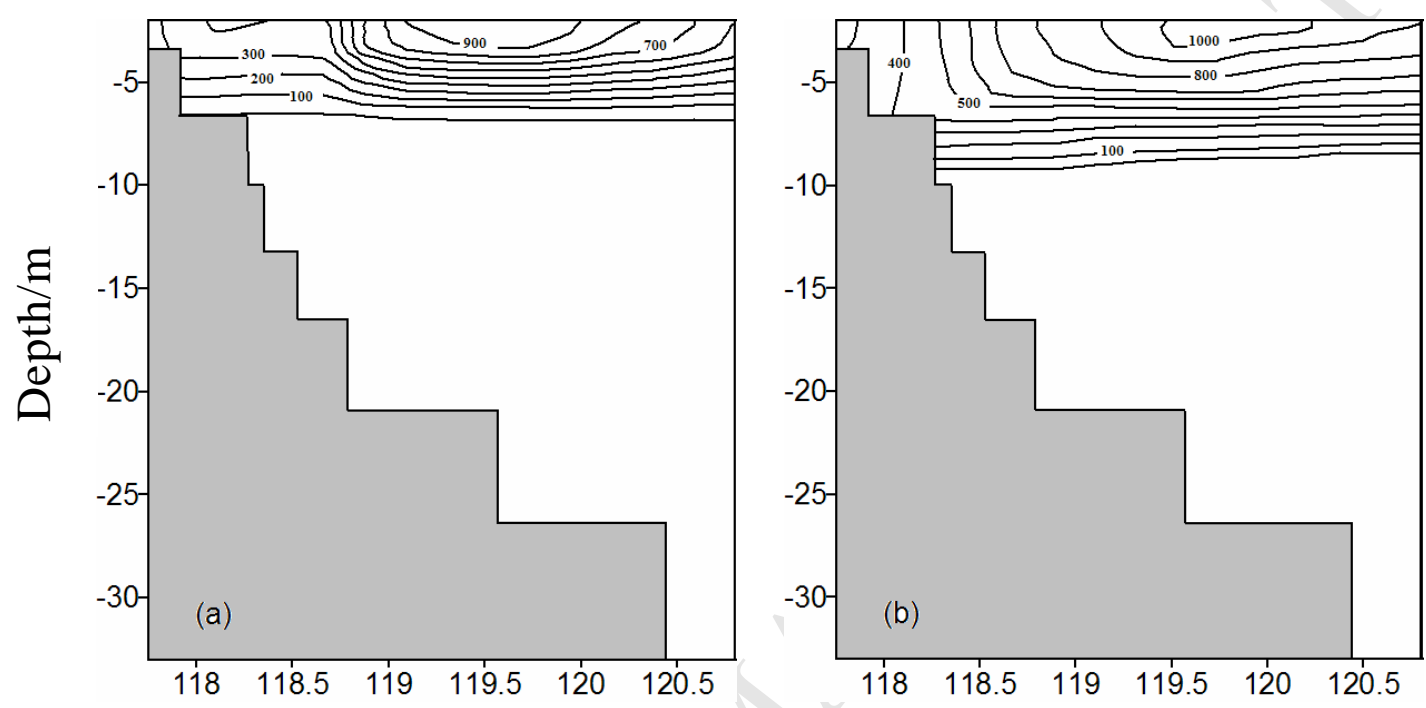

I nnoitude/oF

Fig.6 Comparisons of observed (left plot) and simulated (right plot) primary production profiles $\left(\mathrm{mg} \mathrm{C} \mathrm{m}^{-2} \mathrm{~d}^{-1}\right.$ ) along the cross section i-i in August 1982 

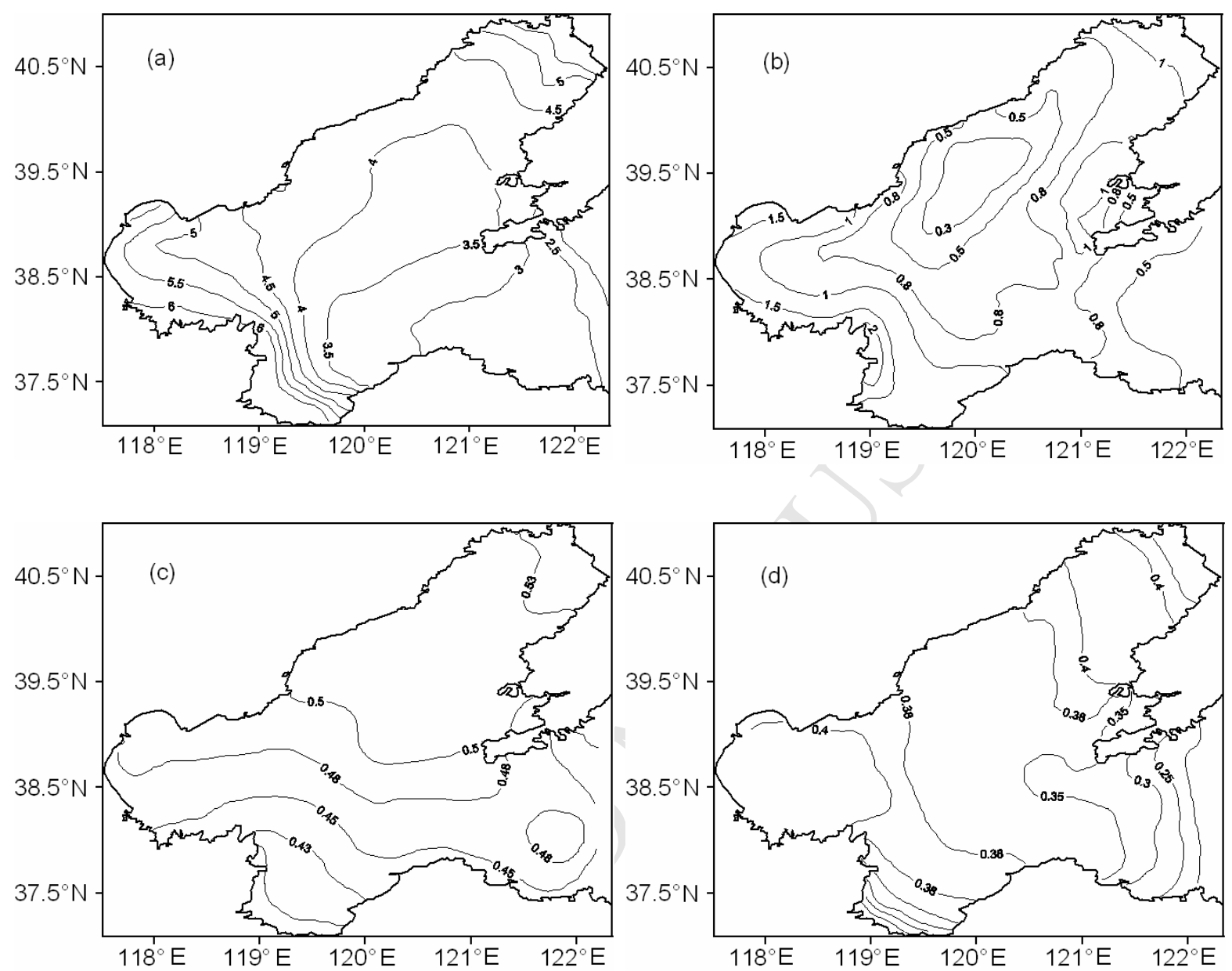

Fig.7 Horizontal distribution of nitrogen $\left(\mathrm{mmol} \mathrm{N} \mathrm{m}^{-3}\right)$ in (a) Jan, (b) July, and phosphorus ( $\left.\mathrm{mmol} \mathrm{P} \mathrm{m}^{-3}\right)$ in (c) Jan, (d) July in the surface layer of BS. 


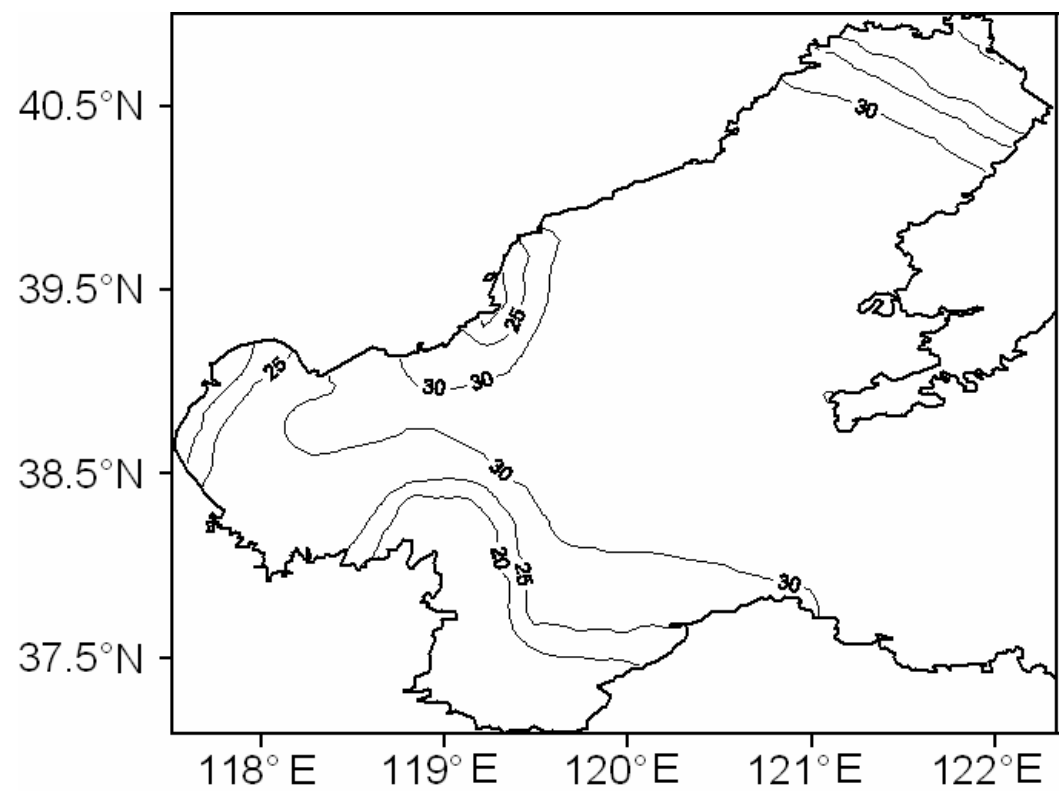

Fig.8 Horizontal distributions of sea surface salinity (psu) in the wet season, and the 30psu contour can be tentatively regarded as the partition between river water and sea water. The contour interval is $\mathbf{5}$ psu. 

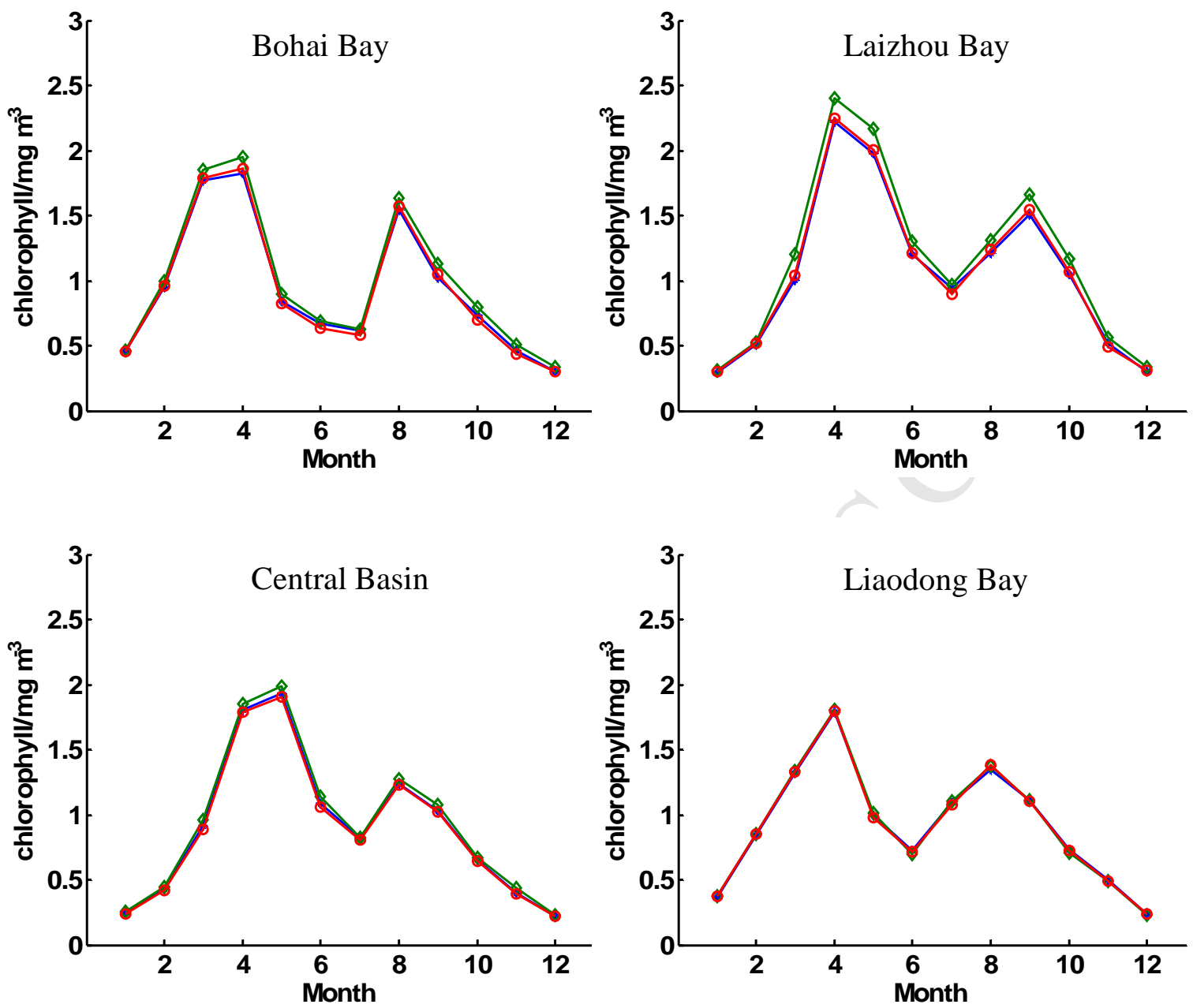

Fig.9 Simulated monthly mean chlorophyll-a in an annual cycle for four parts of BS.

Solid line with star, diamond and open circle indicate the standard case, nitrogen enrichment and phosphorus enrichment, respectively. 

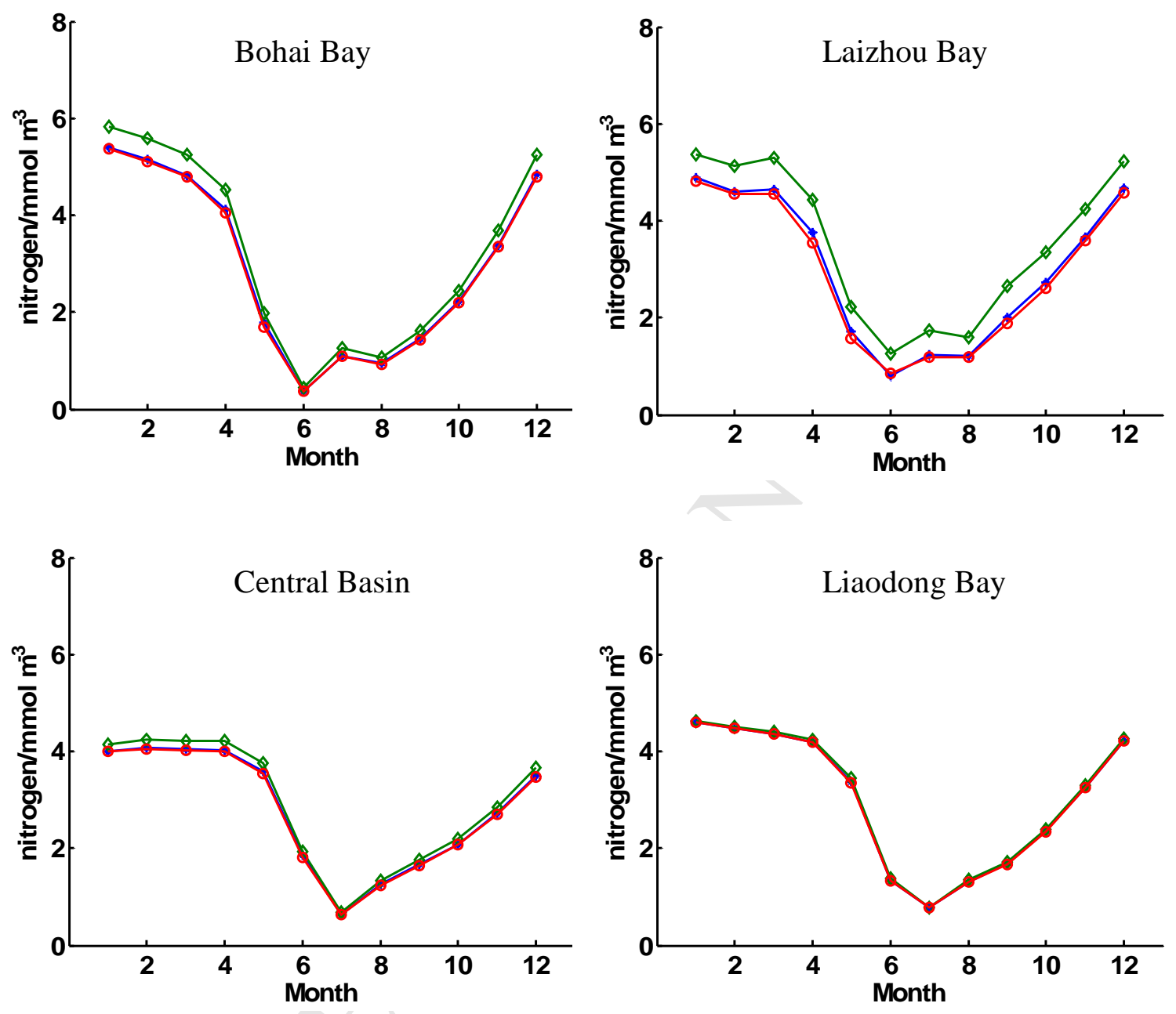

Fig.10 Same as Figure 9, but for nitrogen 

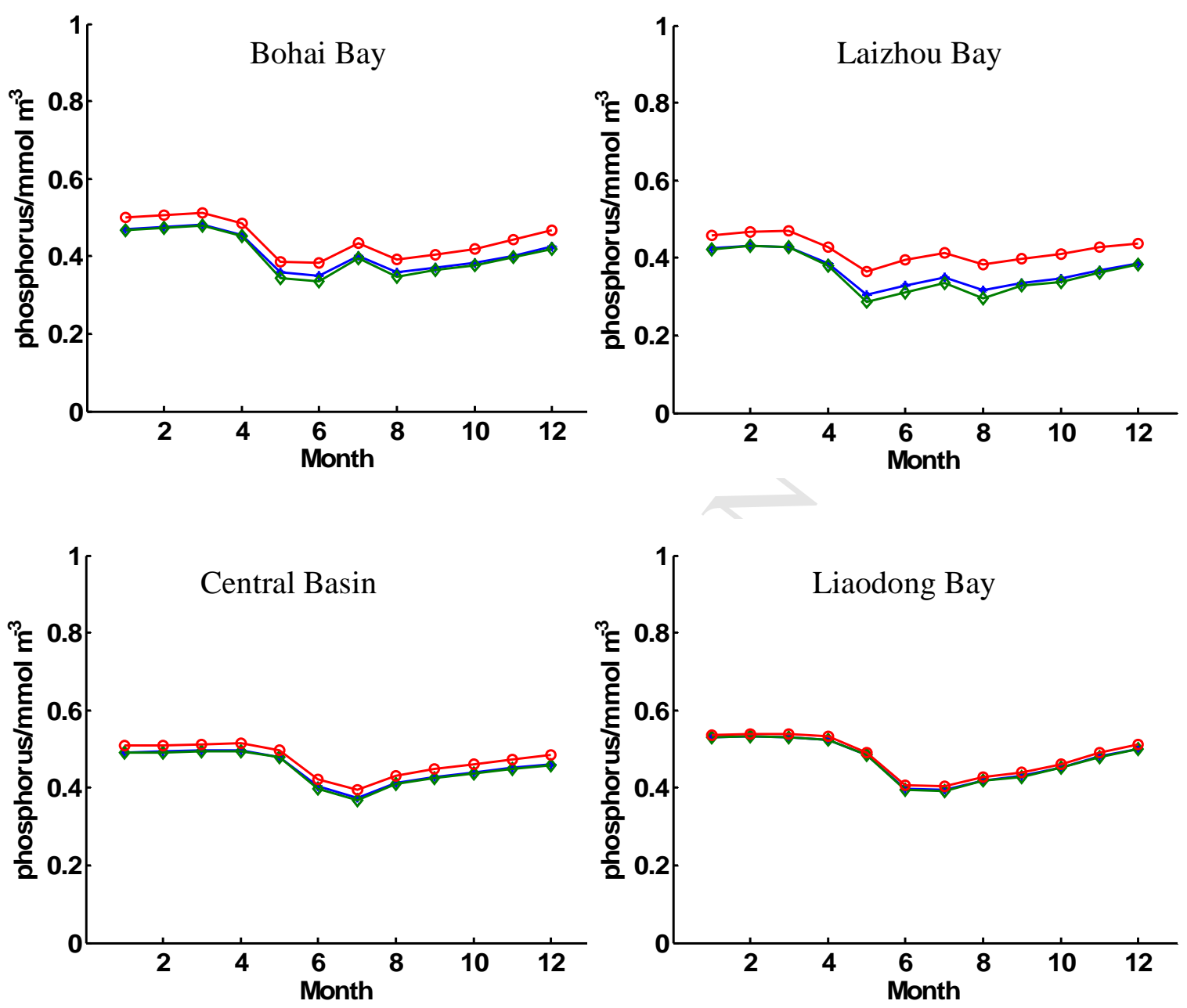

Fig.11 Same as Figure 9, but for phosphorus 